\title{
LO QUE EL PERÚ TIENE POR LA PRESENCIA DE PIZARRO'
}

José Antonio del Busto

uestro compromiso no es con Francisco Pizarro, es con el Perí.
Nos referimos a un Perí integral en el que hablamos de todas las personas. Comencemos por Pizarro. No es el caso de estar de acuerdo o en desacuerdo con la forma en que llevó a cabo la conquista del Tahuantinsuyo. Ese es otro tema. La evidente es que más allá de este asunto discutible está el hecho indiscutible de lo que el Perú es y lo que el Perú será. Ambas cosas están vinculadas a la procedencia y presencia de Francisco Pizarro en el Peru. Por eso, tiene que reconocérsele y aceptársele como autor y actor de algo irreversible que nuestra realidad no debe desconocer. Con esta finalidad, hemos escrito estas líneas, esbozando lo que el Perú es y lo que el Perú posee, directa o indirectamente, debido a Francisco Pizarra

Se puede hablar de Pizarro sin el Perú, pero no se puede explicar el Perú sin Pizarro. Hagamos la prucba, resulta imposible. Luego, nos guste o disguste, es pieza inamovible de nuestro pasado. La lista anunciada no es larga, pero sí importante. Se puede enumerar así el Perí tiene hoy, debido a la presencia de Pizarro, los siguientes hechos: su descubrimiento; su nombre; su ingreso a la Historia, a la Geografia y a la cronología modernas; 
su territorio mayoritario; la Amazoní; las principales ciudades; la cultuma occidental; la lengua española; la religión cristiana; el mestizaje; la nación en su momento; y la cultura peruana. Empecemos.

\section{Su descubrimiento}

Pizarro es el descubridor del Perú. Es su descubridor histórico, consciente y definitivo, el conductor de la empresa descubridora, no un hallador casual ni un buscador furtivo. Avistó el actual territorio peruano en diciembre de 1527, en el segundo de sus tres viajes. No solo avistó Tumbes y toda la costa norteña, sino también la Cordillera de los Andes, que se llamó Sierra Morena. Recorrió en barca desde Tumbes hasta la desembocadura del río Santa, con lo cual se convirtió, asimismo, en el primer curopeo que navegó el marperuano.

\section{Sunombre}

También, debe el Perú a Pizarro la proclamación de su nombre a escala mundial. El nominal «Perú», palabra mestiza, se inspiró en unos indios que hablaron mal y en unos españoles que oyeron peor. No fue Pizarro el creador del topónimo, pero sí su conservador y su mayor difusor. Nuestro territorio, a partir de Pizarro, no fue ya el Tahuantinsuyo de los Incas ni la Nueva Castilla de los Consejeros de Indias, sino una nueva realidad. En otras palabras, si el Perú se llama hoy Perí, es por Francisco Pizarro, y si nosotros nos llamamos peruanos, también es por él. 


\section{Suingreso a la historia}

Igualmente, el ingreso del Perú a la Historia se debe a Francisco Pizarro. Antes de Pizarro, al Perú se le desconocía en Europa, Asia, América y Oceanía, también en América del Norte. Pero debido a Pizarro, nuestro pais ingresó a la Historia del Perú, a la Historia de América, a la Historia de España y a la Historia Universal. Así, acabó el Perú como mito (el Binú), también como leyenda (el Pirui), y se convirtió en historia auténtica (el Perí).

\section{Su ingreso a la geografia}

También, adeuda el Perí a Pizarro su ingreso a la Geografia. Recién a partir de 1527 el Perú tuvo un lugar en el globo tertáqueo con longitud y latitud. Dejamos de ser tierra incógnita para figurar entre paralelos y meridianos, vale decir, cobramos presencia estable e identidad cartográfica en el Padrón del Piloto Mayor de la Indias de la Casa de la Contratación. A través de esta institución sevillana, el mundo conoció cientificamente al Perú geográfico de Pizarro.

\section{Su ingreso a la cronología}

Por un camino similar, llegamos a la cronologia occidental, que es la que nos rige hoy. Su entrada al tiempo histótico brindó al Perú presencia existencial enlo temporal. El Perú se insertó en el calendario de Pizarro y, por consiguiente, en la era cristiana, que es la oficial en el Perú y en el mundo occidental. 


\section{Su territorio mayoritario}

El Perú también debe a Pizatro casi la totalidad de su territorio, pues al oponerse y derrotar a Diego de Almagro impidió que fueran de Chile (entonces gobernación de Nueva Toledo) los actuales departamentos de Ia Libertad, Ancash, Huánuco, Pasco, Junin, Lima, Ica, Huancavelica, Ayacucho, Apurimac, Cusco, Arequipa, Moquegua, Tacna y Puno (sin contar Arica y Tarapacá). De haber ganado Almagro, el Perú sin la Amazonía, se habría limitado a Tumbes, Piura, Lambayeque y Cajamarca. El actual territorio peruano, en su totalidad, se debe a dos personajes insospechados: uno es el Inca Túpac Yupanqui, que ganó y perfiló nuestro actual territorio; el otro es Francisco Pizarro, que también ganó este territorio por armas, lo defendió y supo conservar, y aumentó su dimensión más grande de lo que es ahora. Ambos personajes son los mayores forjadores de la extensión territotial del Perú; en otras palabras, sus autores.

\section{La amazonia}

Otro aporte de Pizarro al Perú es la Amazonía, Los derechos del Perí sobre ella, debidos a Pizarro, estuvieron bastante más allá de nuestros territorios amazónicos actuales. En efecto, al nombrar Francisco Pizarro arbitrariamente a su hermano Gonzalo Gobernador de Quito, hizo que el descubrimiento del Río Grande de las Amazonas perteneciera al Perú y no a la inexistente gobernación quiteña. Tales derechos se reafirmaton con el fracaso de la conquista de la Nueva Andalucía por Francisco de Orellana. Empero, estos limites pizarristas de la Amazonía peruana fueron recortados por el Tratado de San Ildefonso y los posteriores arreglos republicanos. Hoy, gracias a 
Pizarro, el Perú tiene selva - su tercera región natural - y los departamentos de Amazonas, San Martín, Loreto, Ucayali y Madre de Dios. Pero, inicialmente, la Amazonía de Pizarmo iba más allá: rebasaba el Napo (Ecuador), el Putumayo (Colombia), el Yavarl (Brasil), el Beni y el Mamoré (Bolivia). Revisemos el mapa para apreciar cuál fue la Amazonía que nos dejó Pizarro y cuál es el que tenemos ahora.

\section{Sus principales ciudades}

En el Perú, Pizarro fundó, al hispánico modo, las diez principales y más antiguas ciudades del país. Todas existen; ninguna se extinguió. Entre nosotros, nadie ha fundado tantas ciudades; en América, tampoco existen diez ciudades que se deben a un solo fundador y que, además, subsistan. Seis fueron las ciudades fundadas personalmente por Pizarro: Piura, Cusco, Jauja, Lima, Trujillo y Huamanga; y cuatro por medio de sus lugartenientes: Chachapoyas, Moyobamba, Huánuco y Arequipa. Desde otra óptica, a Pizarro no se le debe la destrucción de ninguna ciudad indígena, pero sí su prosecución y continuidad, caso del Cusco, Cajamarca y Huánuco, Cochabamba, Tumibamba y Quito. Desde este punto de vistá, él es el conservador de ciudades incaicas por antonomasia.

\section{La cultura occidental}

La cultura occidental es la heredera de las culturas egipcia, mesopotámica, judía, fenicia, griega, romana, goda, árabe y cristiana medieval. Llegó a nosotros con Pizarto y produjo aquí cambios importantísimos en los órdenes histórico, geográfica, cronológico, político, social, religiosa, técriico, idiomático, económico, 
alimenticio, artístico e intelectual. Para comprobar su importancia en el Perú, basta datar a las ciencias y a las letras, a las matemáticas y al derecho. Es la cultura que hoy, prácticamente, destaca más en el mundo.

\section{Lalengua espafiola}

La lengua española es otro legado de Pizarro. Actualmente, la hablan más del $75 \%$ de los peruanos, sin contar los bilingües. Es una de las principales del orbe y tiende a crecer abrumadoramente. Es una lengua muy rica. En 1992, tenía 85, 500 palabras y la hablaban 300 millones de personas. Es una lengua grafa. Pizarro no la supo escribir ni leer, pero sí hablar. Hoy, el Perú es un adalid por su valiosa producción literaria en lengua espan̂ola.

\section{La religión cristiana}

Pizarro no era un santo ni pretendía serlo, pero fue el implantador del cristianismo en el Perú, que trajo en su versión española el catolicismo, y esta fe, predicada bien o mal a todo el territorio, fue la primera forma de unidad que hemos tenido. La religión católica llevó consigo su dogma y su moral. Nos enseñó a diferenciar, a la cristiana manera, lo bueno y lo malo, lo justo y lo injusto, lo derecho y lo falso. En esto el cristianismo se adelantó con su prédica en muchos siglos a la proclamación de los derechos humanos.

\section{El mestizaje}

El mestizaje, entendido comolo entendemos hoy — «todas las sangres»también comienza con Pizarro. El Perú no es de los cobrizos ni de los 
blancos, tampoco de los negros, de los amatillos ni de los aceitunados: el Perú es de los peruanos. El Perú es cholo, mestizo, y su mestizaje es doble: tacial y cultural. El mestizaje racial, que no sé puede detener, es muy fácil de entender. Si tienes la cara clara, tus rietos la tendrán más oscura; si tienes la cara oscura, tus nietos la tendrán más clara, Somos mestizos, conformamos una nueva realidad, incluso una nueva raza. Para comprobarlo, mirémonos al espejo o apreciemos a los que transitan por la calle. Este mestizaje no fue ajeno a Pizarro. Se acostumbró a las mujeres indias, las prefirió a las blancas, por eso, sus cuatro hijos fueron mestizos. El mestizaje cultural abarca lo creativo de los peruanos, su pensamiento y obra. La cultura peruana es el resultado de la cultura andina (diferencia específica) y de la cultura occidental (género próximo). Pero es una cultura propia: nosotros no somos nuestros padres; mi "Yo» me pertenece integramente. Por eso, este mestizaje es tan variado en la comida, el vestido, la habitación, la música, la danza, la pintura, la literatura, la artesanía y hasta la religión, en lo que no afecta al dogma. Los que niegan este mestizaje divagan, carecen de solución. Pero el mestizaje no es un mito, es un axioma. Algún día seremos mestizos plenos-raciales y culturales-; ya lo somos, pero algín día lo seremos más. En la cornunión de ambos mestizajes, está el secreto de su grandeza. También se ha dicho que el mestizaje peruano es ilegítimo. No lo creo, pero supongámoslo. No hay que olvidar el mérito que tiene por sus buenos frutos el hijo bastardo, distinto al matrimonial: díganlo Miguel Grau, héroe máximo del mar peruano; San Martin de Porras, el peruano más conocido en el mundo; Garcilaso, la mejor pluma mestiza de América quinientista; y otros como Cayetano Heredia, Pancho Fierro y Ricardo Palma. Nuestro mestizaje, pues, no es legítimo, ilegítimo nilegitimado, simplemente, es. 


\section{La nación en su momento}

La nación no es ya la unión de raza, territorio, cultura, lengua y religión. Actualmente, no hay ninguna nación con todas estas características. Se trata de una definición irreal y obsoleta. Hoy se entiende por nación a un conjunto de pueblos con un presente, un pasado y futuro común, pueblos que, además, están unidos por la conciencia nacional. Y, entendámoslo, conciencia nacional nos sobra a los peruanos: somos peruanos (factor involuntario), nos sabemos peruanos (factor cognoscitivo), nos sentimos peruanos (factor afectivo) y queremos seguir siendo peruanos (factor volitivo). Se trata de serlo, saberlo, sentirlo y quererlo. Lo último es lo que se llama la libre determinación. A decir verdad, Francisco Pizarro no pretendió nada de esto. Por eso, lo hemos dicho, no es el fundador de la nación peruana. Le faltó intencionalidad. Pero debido a lo que hizo, la nación peruana existe. La lograron principalmente los criollos, los «españoles americanos» de Viscardo, pero se logró para todos los peruanos. Fue algo asi como afirmar: Pizarro fue un analfabeto, pero por él hoy sabemos leet y escribit. No nos lo enseñó, tampoco fue su pronósito hacerlo; pero debido a Pizarro, hoy leemos y escribimos.

\section{Parte de su cultara}

La cultura peruana actual, a la larga, se debe a dos analfabetos; uno es Pachacútec, que no supo leer ni escribir; el otro es Pizarro, que solo supo rubricar. El quechua representa a la cultura andina o autóctona; el extremeño, a la cultura occidental o europea. La cultura peruana es hija de ambas, pero distinta, independiente y nueva. La cultura occidental es nuestro género 
próximo y nos hace iguales a todos los pueblos de Óccidente; la cultura andina es nuestra diferencia específica y nos hace distintos a todos los países del orbe; es decir, somos universales y singulares. Si por la cultura occidental somos múltiples, por la cultura andina somos únicos. La cultura peruana es nuestra cultura kyoias, es la que expresa y representa nuestro "Yom. No es estática, es evolutiva, fluye. Se debe a utodas las sangres", no solo a la aborigen y a la europea, por lo que también tienen cabida el aporte negro o africano, el aporte amarillo o asiático y el aporte que llamamos aceitunado u oceaniano, con raíces en las Tuamotú y Rapa Nui. Pero todo esto hemos de canalizarlo dentro de la corriente peruanista que sabe aceptar lo bueno y rechazar lo malo. Aqui se agradece el aporte positivo de todos nuestros antepasados y reconocemos que gracias a ellos y a las culturas que te presentaron hoy tenemos un Perú independiente, uninacional, pluricultural, multilingüe y mestizo. Este es el Perú en que vivimos. 


\section{Nota}

'El presente texto fue leído por el renombrado historiador peruano José Antonio del Busto durante el seminario «Forjadores de la identidad peruana», organizado por la Universidad Católica Sedes Sapientiae en el año 2002. Contamos con el consentimiento expreso del autor para la publicación de este texto. 